Article

\title{
Electrochemical Impedance Spectroscopy and Determination of the Internal Resistance as a Way to Estimate Lead-Acid Batteries Condition
}

\author{
Włodzimierz Majchrzycki ${ }^{1}$, Ewa Jankowska ${ }^{1}$, Marek Baraniak ${ }^{2}$, Piotr Handzlik ${ }^{3, *}(\mathbb{D})$ and \\ Robert Samborski ${ }^{4}$ \\ 1 Institute of Non-Ferrous Metals, Division in Poznan Central Laboratory of Batteries and Cells, Forteczna 12, \\ 61-362 Poznan, Poland; wlodzimierz.majchrzycki@claio.poznan.pl (W.M.); \\ ewa.jankowska@claio.poznan.pl (E.J.) \\ 2 Institute of Chemistry and Technical Electrochemistry, Faculty of Chemical Technology, Poznan University \\ of Technology, Berdychowo 4, 60-965 Poznan, Poland; marek.baraniak@put.poznan.pl \\ 3 Department of Physical Chemistry and Metallurgy of Non-Ferrous Metals, Faculty of Non-Ferrous Metals, \\ AGH University of Science and Technology, Mickiewicza 30, 30-059 Cracow, Poland \\ 4 The National Institute of Telecommunications, Szachowa 1, 04-894 Warsaw, Poland; R.Samborski@itl.waw.pl \\ * Correspondence: phandzli@agh.edu.pl; Tel.: +48-12-617-41-24
}

Received: 1 August 2018; Accepted: 2 November 2018; Published: 12 December 2018

check for updates

\begin{abstract}
Attempts have been made to find the best procedure for the detection of premature battery capacity loss (the so called "PCL") in AGM-VRLA 48 V batteries operating in telecommunication systems. However, recorded changes in internal resistance and potential did not give clear indications of the beginning of the PCL effect. The obtained correlation between internal resistance and potential derived from used batteries does not show the expected trend in measured parameters. It seems that the application of Electrochemical Impedance Spectroscopy (EIS), which is a faster and non-destructive method, may solve this problem. It is demonstrated that the change in internal resistance (which is an indicator of the state of health $(\mathrm{SoH})$ ) can be determined from EIS spectra during continuous operation of $12 \mathrm{~V}$ monoblocks in a backup power source of a base transceiver station (BTS).
\end{abstract}

Keywords: PCL-effect; stationary lead acid battery; state of health $(\mathrm{SoH})$; internal resistance; electrochemical impedance spectroscopy (EIS)

\section{Introduction}

Stationary lead-acid batteries are still the most important chemical backup power source used in many technical applications. Therefore, problems with the appropriate level of system safety become more and more important. Detection of increases in the internal resistance may indicate a loss of the real battery capacity [1,2], but this test is not sufficiently reliable. Our investigation carried out on brand new and faulty batteries showed that a battery which is not operating properly may not show changes in its internal resistance [3,4]. It is known that a credible assessment of the battery state consists of its discharge, but this requires that the system be turned off for several hours (like during electrical tests such as discharge by currents lasting for 10 or $20 \mathrm{~h}$ ).

It seems that via electrochemical impedance spectroscopy (EIS), it is more likely that faulty batteries will be detected. The combination of the two above-mentioned techniques should allow for the prediction and/or the identification of battery parts with significant capacity losses, without discharging the battery; the method also shows high reliability [3-8]. 
Battery capacity decrease is caused, among other factors, by: water/electrolyte loss from absorptive glass mat (AGM) separator, grid corrosion, mass sulfation, and drop of mass $[9,10]$. One of the most frequent and less known factors influencing the decrease in lead-acid battery capacity is the Premature Capacity Loss (PCL) effect. PCL affects each type of lead-acid battery. This phenomenon is more frequently studied in a relation to stationary batteries because of their assumed long-term operating time (sometimes over 10 years). The PCL effect is relatively common in the VRLA batteries of AGM type [9-17]. Currently, the problem has been reduced, but as a consequence, very often that the batteries have to be exchanged more frequently, especially in key role systems. Three main models of the process leading to the aforementioned phenomenon have been suggested:

- formation of a low-conducting layer at the grid/active mass interface (PCL of type 1). This is probably the most frequent case of the PCL effect caused by the formation of a passivation layer next to a typical corrosive layer at the grid/active mass interface. This tight coating contains $\mathrm{PbSO}_{4}$, and /or $\mathrm{PbO}_{1 \pm n}$ compounds,

- PCL of the second type is related to an increase in resistance of the pasted active mass (PAM), which can be observed in case of weak adhesion between a grid and the PAM. The corrosive layer consists mainly of $\beta-\mathrm{PbO}_{2}$, and the concentration of sulphuric acid is far higher in this area. Thus, the original spatial structure of the plate is distorted, which causes electrochemical insulation of a part of the active mass. However, a decrease in active mass has not yet been observed.

- irreversible transformation of a superficial part of the active mass (usually negative) into big lead sulphate crystals during cycling (PCL of the third type). Big crystals of $\mathrm{PbSO}_{4}$ are formed gradually, and it is hard to reduce them into metallic $\mathrm{Pb}$ during charging [12-17].

In order to detect undergoing processes, the EIS technique seems to be very well suited. Huet [18] analysed the relationship between various EIS parameters. He concluded that EIS can be an important diagnostic tool. Application of a multi-channel EISmeter for precise measurements on batteries was reported by Blanke et al. [19], who reviewed different approaches to determine SoC, SoH, and cranking capability of lead-acid batteries with the aid of EIS.

Indeed, electrochemical impedance spectroscopy (EIS) is an excellent tool to analyze the interfacial processes, variation in the internal resistance, state-of-charge, and the residual capacity of a lead-acid battery. This method is fast, accurate, nondestructive in nature, and is ideal for the modeling and diagnosis of industrial batteries. It was experimentally confirmed that this technique can be applied to modeling battery behavior, as well as to the determination of the state-of-charge (SoC) and the state-of-health $(\mathrm{SoH})$ [20]. Diard et al. [21] conducted a general EIS study on electrochemical battery discharge at a constant load and constant current; attention was concentrated on the impedance test for a lead-acid battery with high capacity and low impedance at load. The SoH is connected mostly with the ohmic resistance, the charge transfer resistance $R_{c t}$, and the parameters of the constant phase element accounting for the diffusion in the pores when the plate is well charged. In turn, battery modeling is an important issue for the design of different battery applications. Thus, it is necessary to develop a reliable and easy-to-parameterize battery model. However, for lead-acid batteries, impedance spectra depend very much on the short-term charge-discharge history. Karden et al. [20,22] discussed further methodological questions connected with the measurement and interpretation of the impedance spectra of batteries, especially nonlinearity, voltage drift, stability, reproducibility, half-cell measurements, model structure, and parameter extraction from the impedance data.

An alternative approach was suggested by Wei et al. $[23,24]$ who assessed the battery state by adopting a first-order RC model and proposing a dully-decoupled procedure which led to joint $\mathrm{SoC}$ and capacity loss $(\mathrm{SoH})$ estimation. This approach was later implemented in an online-monitoring method to detect capacity loss in vanadium redox flow batteries in real time. It was checked experimentally on the laboratory scale battery system and the SoC and the capacity loss was found to be accurately derived in real time. 
The aim of this study is to find correlations between voltage changes, internal resistance, characteristics of electrochemical impedance spectra, and actual capacity of the stationary lead-acid battery. The correlation between these factors would help to determine, as quickly as possible, the initial battery capacity loss, which can be regarded as the beginning of the premature capacity loss (PCL) effect, while the system would still have the capacity to be used safely.

In the present work, we describe the preliminary results of these investigations. The study was undertaken because of the low effectiveness and reliability of existing diagnostic systems used in emergency power supply modules.

\section{Results and Discussion}

During tests, an observed decrease in capacity of a $48 \mathrm{~V}$ battery that had operated in an emergency power supply systems was nearly $30 \mathrm{Ah}$. The capacity after the first, second, and third cycle was $103 \mathrm{Ah}, 82 \mathrm{Ah}$ and $76 \mathrm{Ah}$, respectively. For the new $48 \mathrm{~V}$ battery, the capacity did not change and had a constant value of circa 110 Ah (Table 1).

Table 1. Capacity of a brand new $48 \mathrm{~V}$ battery and the used battery, after float charge tests.

\begin{tabular}{ccc}
\hline Time of Float Charge (d) & $\begin{array}{c}\text { Capacity of a Brand New 48 V } \\
\text { Battery (Ah) }\end{array}$ & $\begin{array}{c}\text { Capacity of a Used 48 V } \\
\text { Battery (Ah) }\end{array}$ \\
\hline $0^{*}$ & 109 & 109 \\
33 & 113 & 103 \\
66 & 114 & 82 \\
99 & 116 & 76 \\
\hline
\end{tabular}

* 0 day-batteries capacity after delivery to tests and after recharging.

Figure 1a,b show changes of internal resistance of a brand new $48 \mathrm{~V}$ battery and used ones during float charges in the first, second, and third stage of tests (during 33, 66 and 99 days).

a)

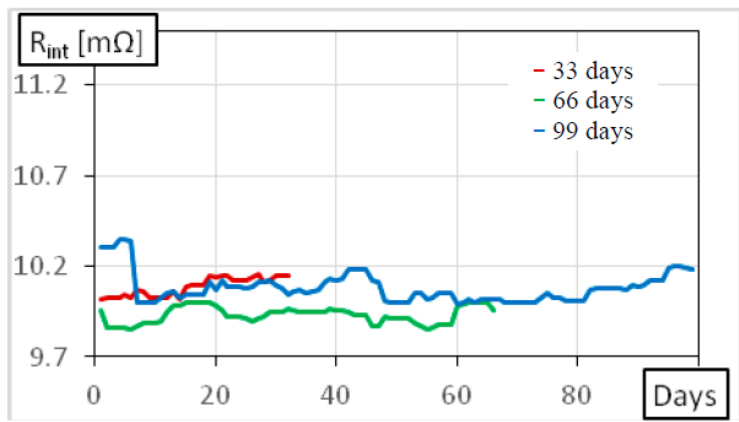

b)

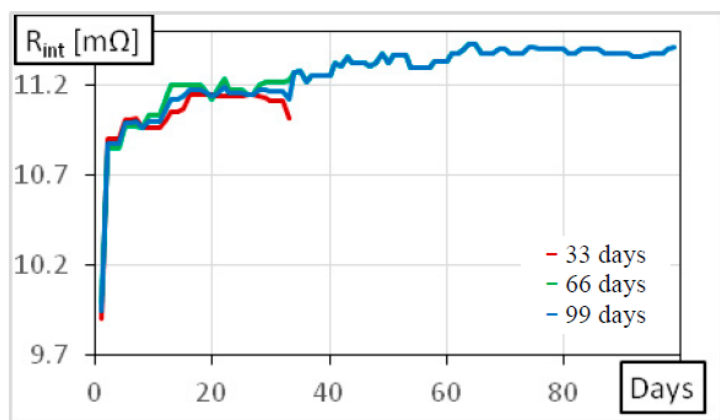

Figure 1. Changes in the internal resistance of $48 \mathrm{~V}$ (a) new battery and (b) used battery during float charge tests.

It can be noted that the internal resistance of a $48 \mathrm{~V}$ system is slightly higher for the used battery than for the new one, and it has a higher amplitude after full charging. However, the values and character of changes of this parameter do not have a correlation with electrical capacity.

Figure $2 \mathrm{a}-\mathrm{f}$ show changes of the potential and the internal resistance of two selected monoblocks with 6 cells after operation in emergency power supply systems, as well as two new ones after 33, 66, and 99 days of a float charge. Selected units of $12 \mathrm{~V}$ had measured values of potential and internal resistances which were very different from those of brand new ones.

Recorded data: $E=f(t)$ and $R_{\text {int }}=f(t)$ indicated that the internal resistance changes were small for systems previously used in emergency power supply systems, as well as for the new ones. An average 
value of the internal resistance (measurements data from 5 days to the end of the test, for completely charged batteries-only float current in a circuit) is presented in Table 2.
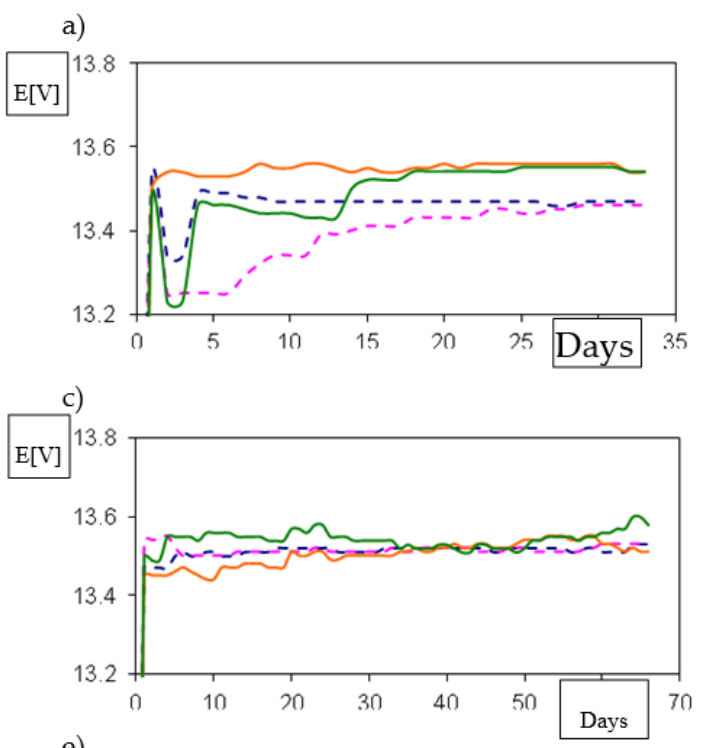

e)

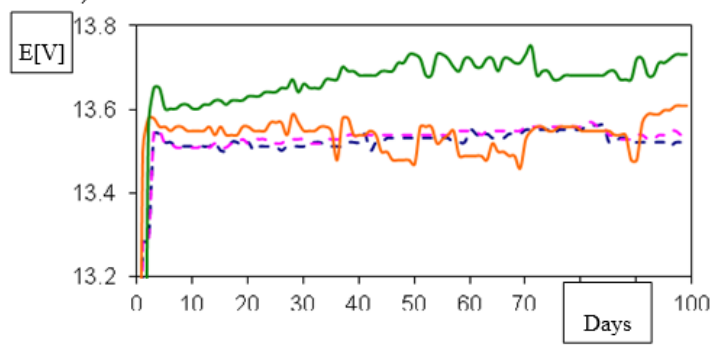

b)

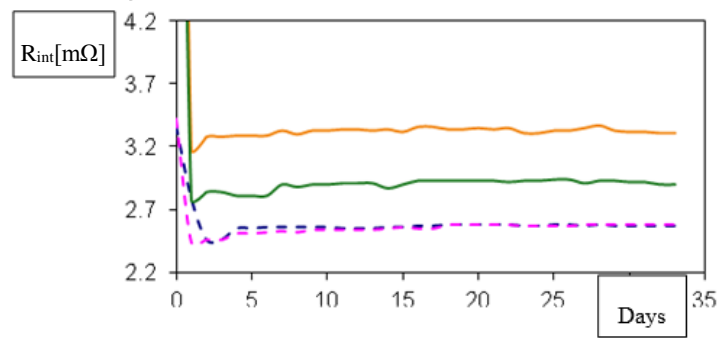

d)

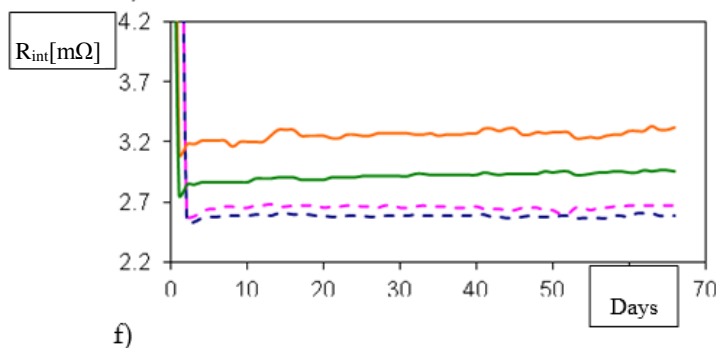

f)

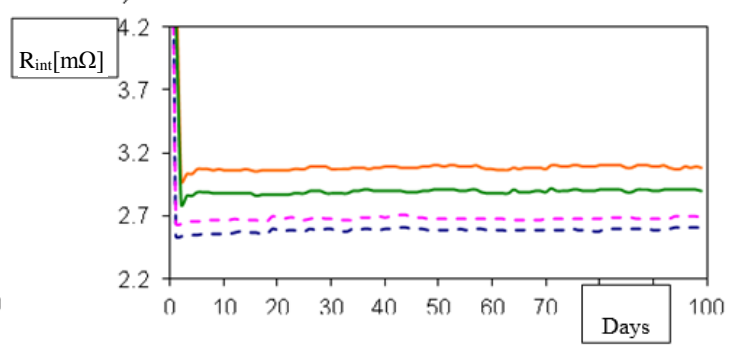

Figure 2. Potential and internal resistance during (a,b) 33 days, (c,d) 66 days, $(\mathbf{e}, \mathbf{f}) 99$ days float charge tests, -two selected brand new $12 \mathrm{~V}$ monoblocks (dotted line), and two selected $12 \mathrm{~V}$ used monoblocks (solid line).

Table 2. Average values of internal resistance for selected brand new $12 \mathrm{~V}$ monoblock and used monoblock during float charge tests.

\begin{tabular}{ccccc}
\hline Test & Brand New $(\mathbf{1})(\boldsymbol{\Omega})$ & Brand New $(\mathbf{2})(\boldsymbol{\Omega})$ & Used $(\mathbf{1})(\boldsymbol{\Omega})$ & Used $(\mathbf{2})(\boldsymbol{\Omega})$ \\
\hline 33 days & 0.0026 & 0.0026 & 0.0033 & 0.0029 \\
66 days & 0.0026 & 0.0027 & 0.0033 & 0.0029 \\
99 days & 0.0026 & 0.0027 & 0.0031 & 0.0029 \\
\hline
\end{tabular}

It is noticeable that after 33 days of float charge tests (the first stage of the test), bigger changes in potential in case of the new $12 \mathrm{~V}$ monoblocks were observed. On one hand, the possible reason for this may be an additional formation process of monoblocks included in $48 \mathrm{~V}$ referential battery. On the other hand, during the third stage, a bigger difference between values of the potential is visible for the $12 \mathrm{~V}$ used units after they stopped working. The measurements of changes in resistance of these two groups of batteries showed that for all three cycles, i.e., 33, 66 and 99 days, the $12 \mathrm{~V}$ monoblocks after service had higher resistance parameters (in average about $3.0 \mathrm{~m} \Omega$ ) than the new ones (in average about $2.6 \mathrm{~m} \Omega$ ), and differences between their values during measurements were insignificant.

The subsequent figures (Figure $3 a-f$ ) show scatter diagrams of the potential and the internal resistance of each $12 \mathrm{~V}$ unit in $48 \mathrm{~V}$ batteries drawn at different time of flow current tests.

It can be noticed that $12 \mathrm{~V}$ units after service had a large potential and internal resistant span on each stage of the presented electric tests. Higher potential and low internal resistance of the units after service suggest "problems" with obtaining a completely discharged state. 
a)

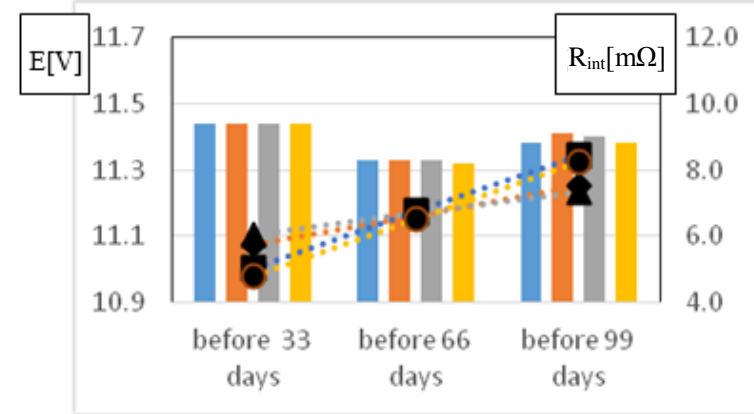

c)

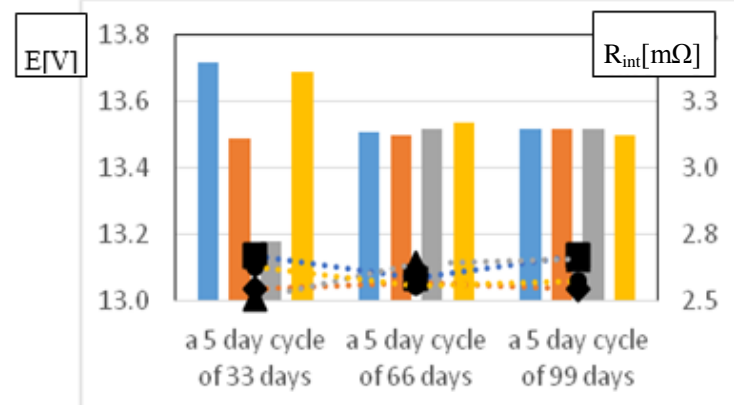

e)

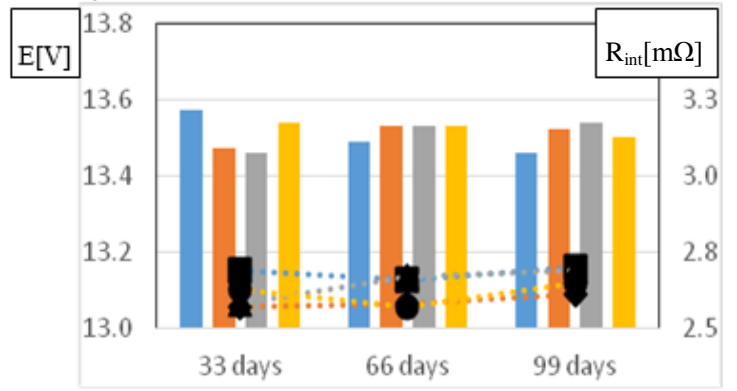

b)

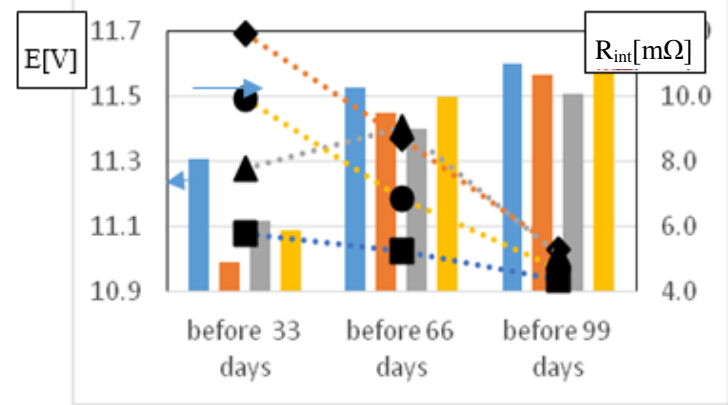

d)

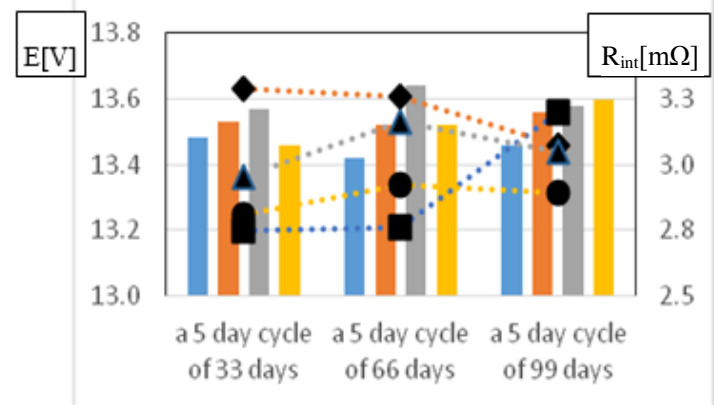

f)

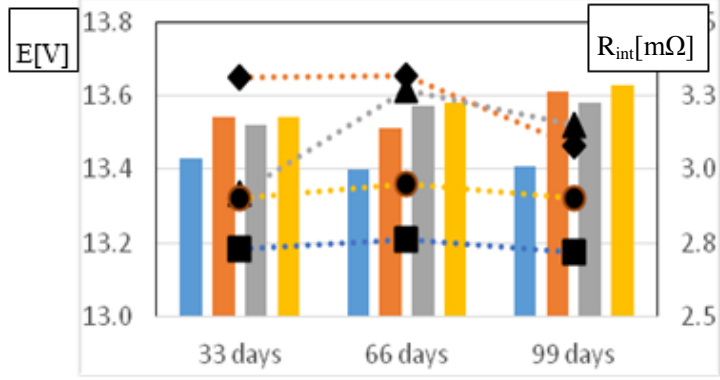

Figure 3. Scatter diagrams of potential (bar graph) and internal resistance (line graph) of single $12 \mathrm{~V}$ monoblocks before start $(\mathbf{a}, \mathbf{b})$, after 5 days $(\mathbf{c}, \mathbf{d})$ and in last days $(\mathbf{e}, \mathbf{f})$ of flow current tests in $48 \mathrm{~V}$ battery: brand new (left-a,c,e), and used (right-b,d,f).

Correlation between internal resistance and potential (on the last day of flow current tests-in 33th, 66th and 99th day) of two selected $12 \mathrm{~V}$ units after service (with the highest differences of internal resistance) and new ones (as referential group) presented in Figures 4 and 5 shows average values of the potential of the units and internal resistance on the last day of current flow experiment, and $2 \mathrm{~h}$ after the end of this test ( $48 \mathrm{~V}$ batteries were in open circuit state).

Differences in the function $R_{i n t}=f(E)$ can be observed for the $12 \mathrm{~V}$ units after operation in emergency power supply systems in comparison with new $12 \mathrm{~V}$ units. It can be noticed that the new $12 \mathrm{~V}$ units (excluding the first stage of current flow test which is probably the continuation of physicochemical changes in the active mass occurred after formation process) presented almost identical correlation $R_{\text {int }}=f(E)$ in the 66th and 99th days. The change of this parameter for $12 \mathrm{~V}$ units after service is not unambiguous, but slight trends in increasing potentials and decreasing internal resistant can be observed. In Figure 5, slight differences in the function $R_{\text {int }}=f(E)$ can be observed for both groups, i.e., in the current flow state and open circuit state ( $2 \mathrm{~h}$ after cutting off the current flow). Lower span of the potential and the internal resistance for new $12 \mathrm{~V}$ units can be noticed. 


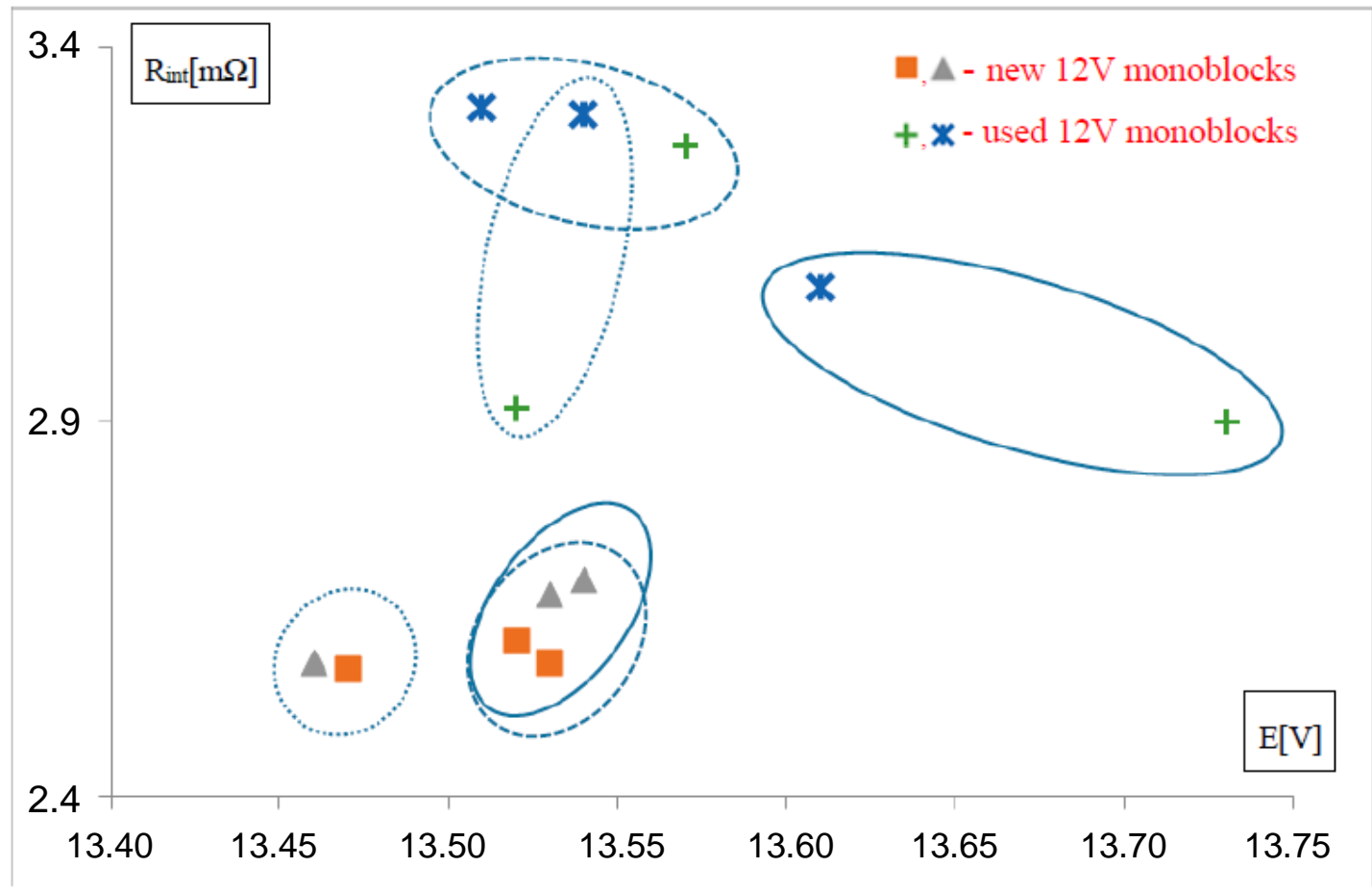

Figure 4. $R_{\text {int }}=f(E)$ on the last day of flow current tests (on the 33th, 66th and 99th day); figure legend: square, triangle-two selected new $12 \mathrm{~V}$ monoblocks; plus and asterisk: two selected used $12 \mathrm{~V}$ monoblocks points in: dotted line area: values after 33 days of testing, discontinuous line area: values after 66 days of testing, solid line area: values after 99 days of testing.

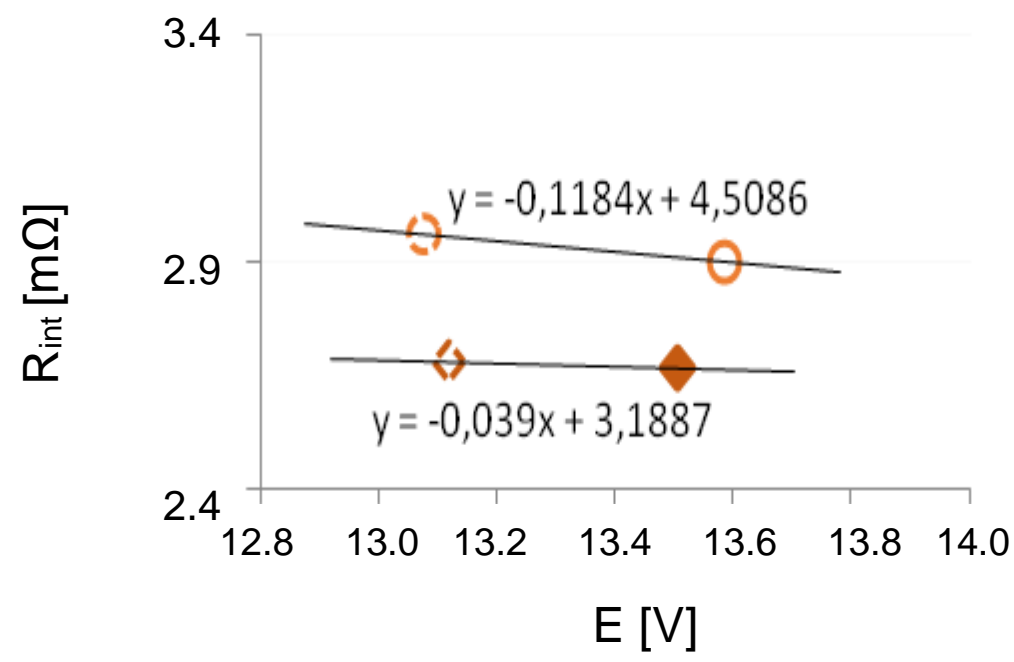

Figure 5. Ratio $R_{\text {int }}=f(E)$ on the 99th day and $2 \mathrm{~h}$ after finishing the flow current tests (each value is an average for two selected $12 \mathrm{~V}$ monoblocks) and the equation of the trend line. figure legend: rhombus-new batteries; circle-used batteries. solid point-before cutting the float current, discontinuous point: $2 \mathrm{~h}$ after cutting the float current.

Another technique used to check the battery's state-of-health was potentiostatic electrochemical impedance spectroscopy (PEIS), applied to $12 \mathrm{~V}$ monoblocks under OCP conditions (after batteries potential stabilization-2 $\mathrm{h}$ after finishing current flow test).

Two groups consisting of three $12 \mathrm{~V}$ units each containing new (one group) and used (another group) batteries were investigated by EIS method after 33, 66, and 99 days of current flow tests. 
Figure 6a presents impedance data for a chosen used battery (No. 12) in the form of Nyquist plots, while Figure $6 \mathrm{~b}$ presents impedance data for a chosen new battery (No. 15).

a)

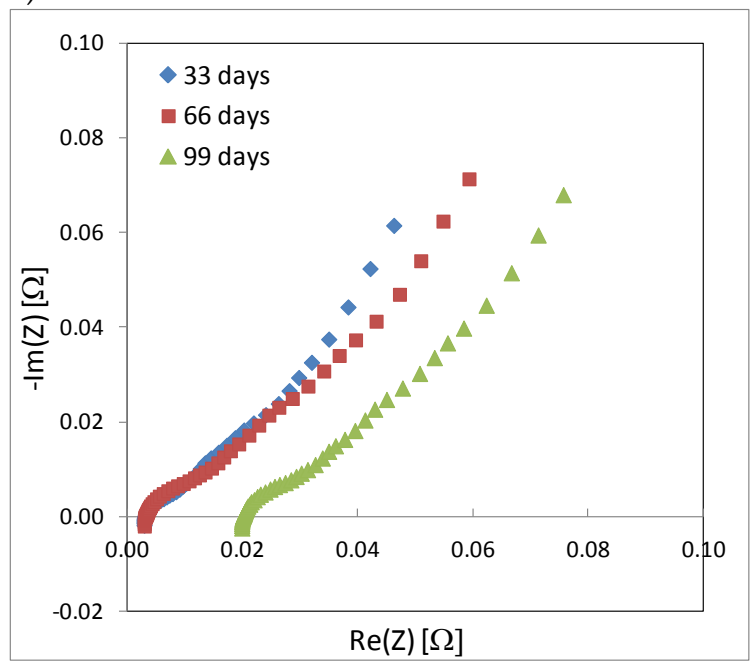

b)

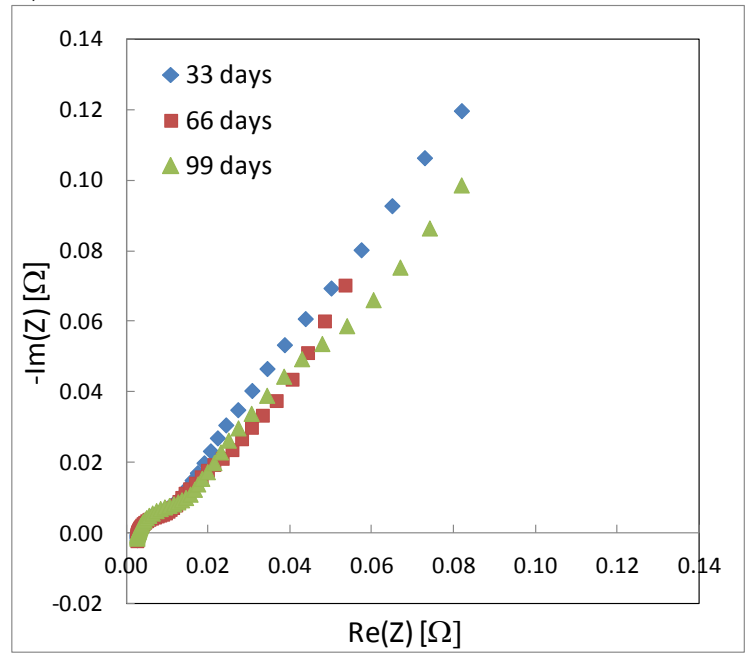

Figure 6. Impedance spectra in the form of Nyquist plots for: (a) $12 \mathrm{~V}$ monoblock of used battery, (b) $12 \mathrm{~V}$ monoblock of new battery.

The impedance spectra shown in Figure 6a,b demonstrate a difference between old and new batteries. It is seen that the Nyquist plot obtained after 99 days of float charge tests for the used battery is shifted to the right in comparison with the same plot obtained for the new battery.

A more quantitative description of the experimental data requires the choice of the proper EEC (electrochemical equivalent circuit). The set of impedance data submitted for a fitting procedure was reduced to frequency range from $1 \mathrm{kHz}$ to $1 \mathrm{~Hz}$ to maintain the linearity of the system's response [25]. The best-suited EEC for reduced impedance data is shown in Figure 7. This is a part of the circuit which was used in many works concerning EIS investigations of lead-acid batteries $[19,25,26]$. The galvanic cell from lead-acid batteries can be fitted well with the model, having following electrical properties:

- inductance $\mathrm{L}_{0}$ attributed to electrode geometry and connections inside the cell,

- resistance $\mathrm{R}_{\mathrm{HF}}$ due to the connections, the separator, the electrolyte resistivity and the surface coverage of the electrodes by crystalline lead sulphate,

- resistance $\mathrm{R}_{1}$ depending on the porosity of the electrodes,

- $\mathrm{CPE}_{1}$ responsible for heterogeneous phenomena.

The constant phase element was used because the surface of the electrode is never ideally flat, and in the electrochemical measurements, this element replaces the ideal capacitor [25]. The impedance of the CPE is described by the equation:

$$
Z_{Q}=\frac{1}{Q(j \omega)^{n}}
$$

where $Q$ is a pre-exponential factor, which is a frequency-independent parameter; $n$ is the exponent, which defines the character of frequency dependence $(-1 \leq n \leq 1) ; \mathrm{j}=\sqrt{-1}$ is the imaginary unit; and $\omega=2 \pi f\left[\mathrm{rad} \cdot \mathrm{s}^{-1}\right]$ is angular frequency. With $n=1, Q$ is an ideal capacitance, and has the unit of capacitance (F); in another case when $n \neq 1, Q$ has the unit of $S \cdot s^{n}$. 


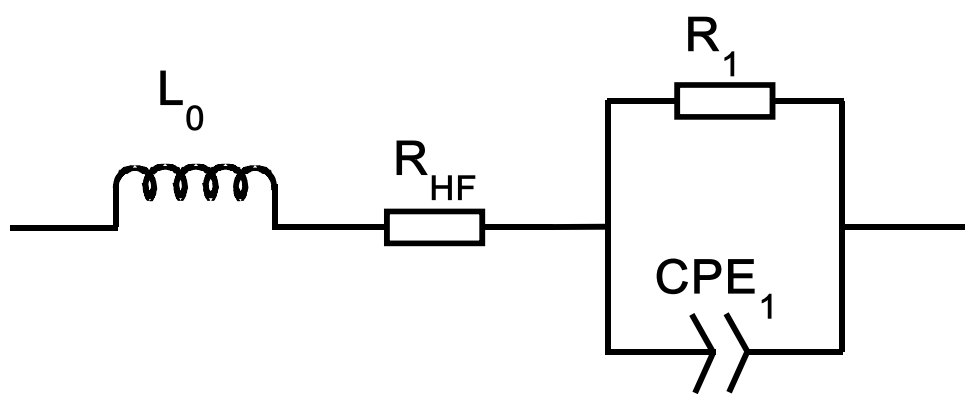

Figure 7. EEC used for modeling of the impedance spectra of $12 \mathrm{~V}$ monoblock.

The results of the experimental data fitting with chosen EEC (Figure 7) are given in Table 3. To show that all data are well described with accepted EEC, Nyquist and Bode plots for the experimental and simulated data are shown in Figure 8. The experimental data gathered in Table 3 demonstrate that the resistance $R_{H F}$ increases after 99 days by almost one order in magnitude (from circa $3 \mathrm{mOhms}$ to $20 \mathrm{mOhms}$ ) for used batteries. This resistance change may indicate the beginning of the PCL effect in the battery. This result seems to be reliable, since simulations of EIS spectra with accepted EEC agree well with the experimental results (Figure 8).

The idea of the application of electrochemical impedance spectroscopy for determination of SoH and $\mathrm{SoC}$ is not a new one. In the case of industrial batteries, it was discussed, e.g., by Huet [18] and Karden et. al. [20,22]. However, the main problem lies in the interpretation of obtained impedance spectra. The choice of an equivalent circuit is not always universal. In our case, an increase in the resistance for the used batteries was detected, which is a very encouraging result for this non-destructive test. Unfortunately, it seems to be the only reliable information extracted from impedance spectra which can help to detect PCL effect. We found that for the low frequency range, it is difficult to find the proper EEC. More work is needed to work out a general approach to solve this problem.

Table 3. Obtained results for impedance spectra according to the fit of EEC shown in Figure 7.

\begin{tabular}{cccccc}
\hline No. of Battery-Days & $\mathbf{L}_{\mathbf{0}} \mathbf{( H )}$ & $\mathbf{R}_{\mathbf{H F}}(\boldsymbol{\Omega})$ & $\mathbf{R}_{\mathbf{1}}(\boldsymbol{\Omega})$ & $\mathbf{Q}^{\mathbf{O}}\left(\mathbf{S} \cdot \mathbf{s}^{\mathbf{n}}\right)$ & $\mathbf{n}$ \\
\hline U9-33 & $2.83 \times 10^{-7}$ & 0.00276 & 0.03350 & 22.27 & 0.75 \\
U9-66 & $3.02 \times 10^{-7}$ & 0.00275 & 0.02449 & 18.38 & 0.78 \\
U9-99 & $3.52 \times 10^{-7}$ & 0.01950 & 0.01879 & 24.70 & 0.72 \\
U10-33 & $2.68 \times 10^{-7}$ & 0.00315 & 0.01724 & 27.31 & 0.71 \\
U10-66 & $2.89 \times 10^{-7}$ & 0.00330 & 0.02405 & 17.67 & 0.78 \\
U10-99 & $3.69 \times 10^{-7}$ & 0.01370 & 0.02088 & 18.62 & 0.78 \\
U12-33 & $2.89 \times 10^{-7}$ & 0.00288 & 0.01870 & 28.53 & 0.70 \\
U12-66 & $3.14 \times 10^{-7}$ & 0.00299 & 0.02335 & 18.34 & 0.77 \\
U12-99 & $3.80 \times 10^{-7}$ & 0.01990 & 0.02210 & 18.80 & 0.77 \\
N13-33 & $2.97 \times 10^{-7}$ & 0.00270 & 0.01817 & 18.83 & 0.77 \\
N13-66 & $3.06 \times 10^{-7}$ & 0.00258 & 0.01664 & 20.05 & 0.75 \\
N13-99 & $2.94 \times 10^{-7}$ & 0.00267 & 0.02458 & 14.12 & 0.81 \\
N14-33 & $3.27 \times 10^{-7}$ & 0.00258 & 0.02084 & 16.93 & 0.79 \\
N14-66 & $3.25 \times 10^{-7}$ & 0.00254 & 0.01569 & 19.12 & 0.76 \\
N14-99 & $2.51 \times 10^{-7}$ & 0.00260 & 0.02276 & 14.11 & 0.81 \\
N15-33 & $3.01 \times 10^{-7}$ & 0.00260 & 0.02014 & 17.36 & 0.79 \\
N15-66 & $3.48 \times 10^{-7}$ & 0.00256 & 0.01606 & 18.63 & 0.76 \\
N15-99 & $2.28 \times 10^{-7}$ & 0.00261 & 0.02302 & 14.16 & 0.81 \\
\hline
\end{tabular}


a)

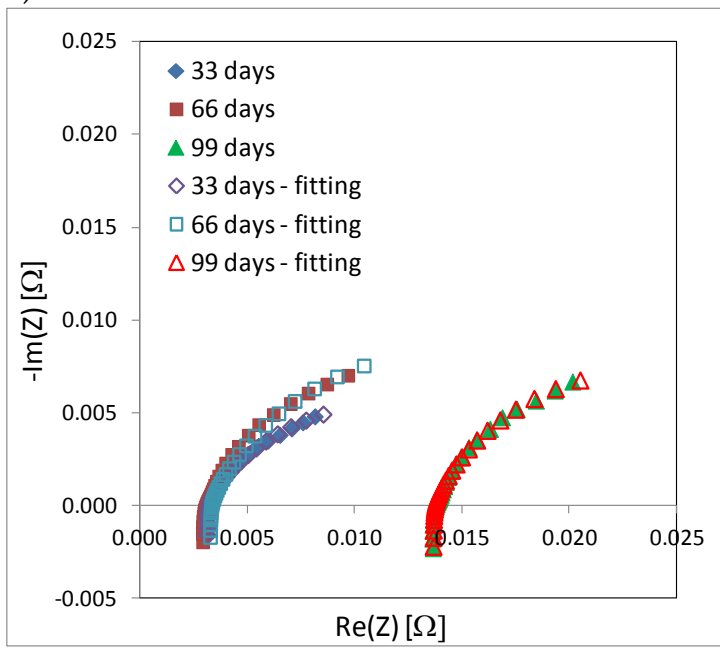

c)

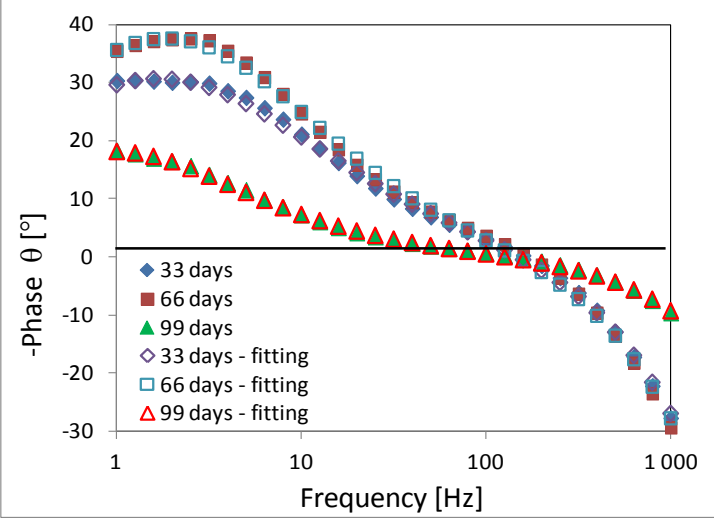

b)

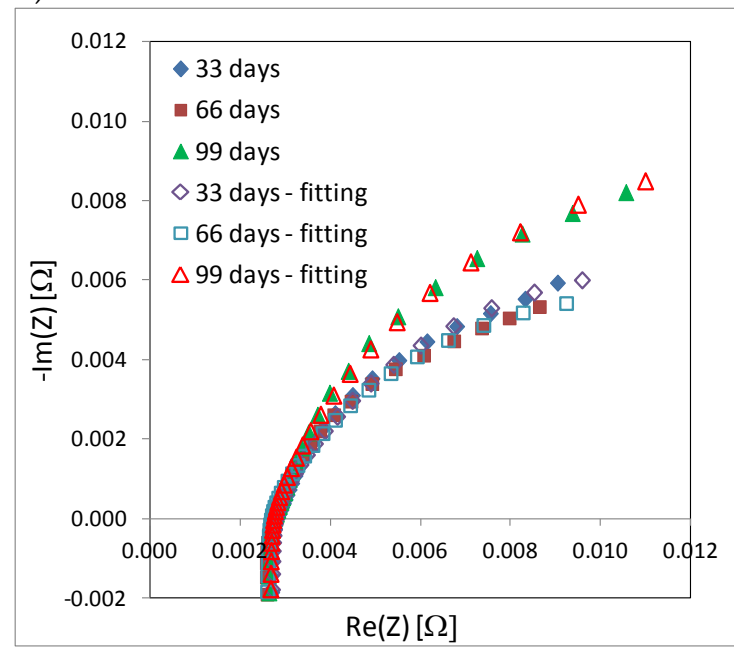

d)

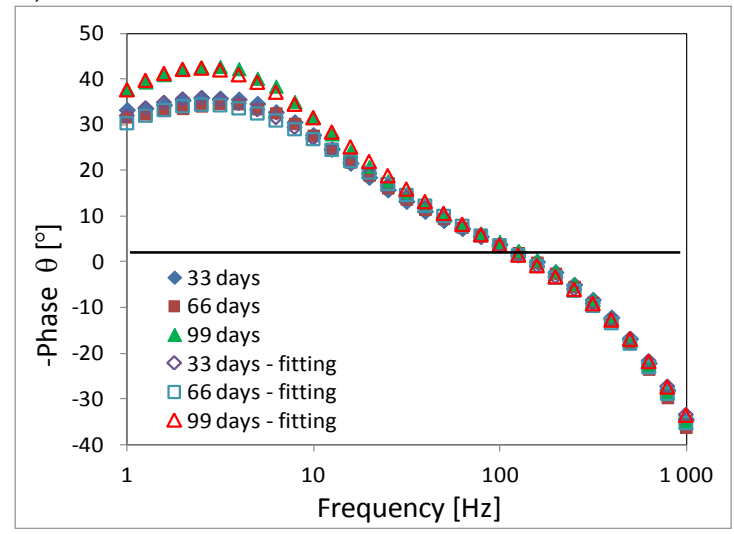

Figure 8. Experimental and fitting data in the form of Nyquist and Bode plots for: (a,c) $12 \mathrm{~V}$ monoblock of used battery, $(\mathbf{b}, \mathbf{d}) 12 \mathrm{~V}$ monoblock of new battery.

\section{Materials and Methods}

Analysis of many correlations between physicochemical features, exploitation conditions, and electrical properties and their influence on the capacity indicated several problems:

- Acquiring already used battery with a known history, in order to increase the probability of detection of the PCL effect,

- The mildness of the initial physicochemical changes accompanying the PCL effect,

- The choice of tests and the testing conditions,

- The appropriate classification of these changes and their assignment to the area of the PCL effect (or other).

To reduce these problems, the experimental material consisted of two groups of $12 \mathrm{~V}$ batteries (hereafter called "monoblocks", in order to distinguish them from the 48 V system) AGM-VRLA with capacity of $100 \mathrm{Ah}\left(\mathrm{C}_{10}\right)$. The 6-cell monoblocks of the first group had operated in emergency power supply systems in a telecommunication station for over 4 years. Those systems consisted of two batteries, and each battery included four monoblocks with 6 cells in every monoblock (each monoblock had $12 \mathrm{~V}$ nominal potential). The system is very popular in mobile telephony base stations. The 6-cell monoblocks of the second group were brand new, and were made by the same manufacturer. The brand new pieces were used as referential ones. Construction of the cells from both groups of $12 \mathrm{~V}$ monoblocks (e.g., both-type AGM-VRLA-Figures 9 and 10, number of positive and negative plates, 
and grid construction almost identical-Figure 11) indicated that almost all differences in electrical and electrochemical properties should be associated with the usage history.

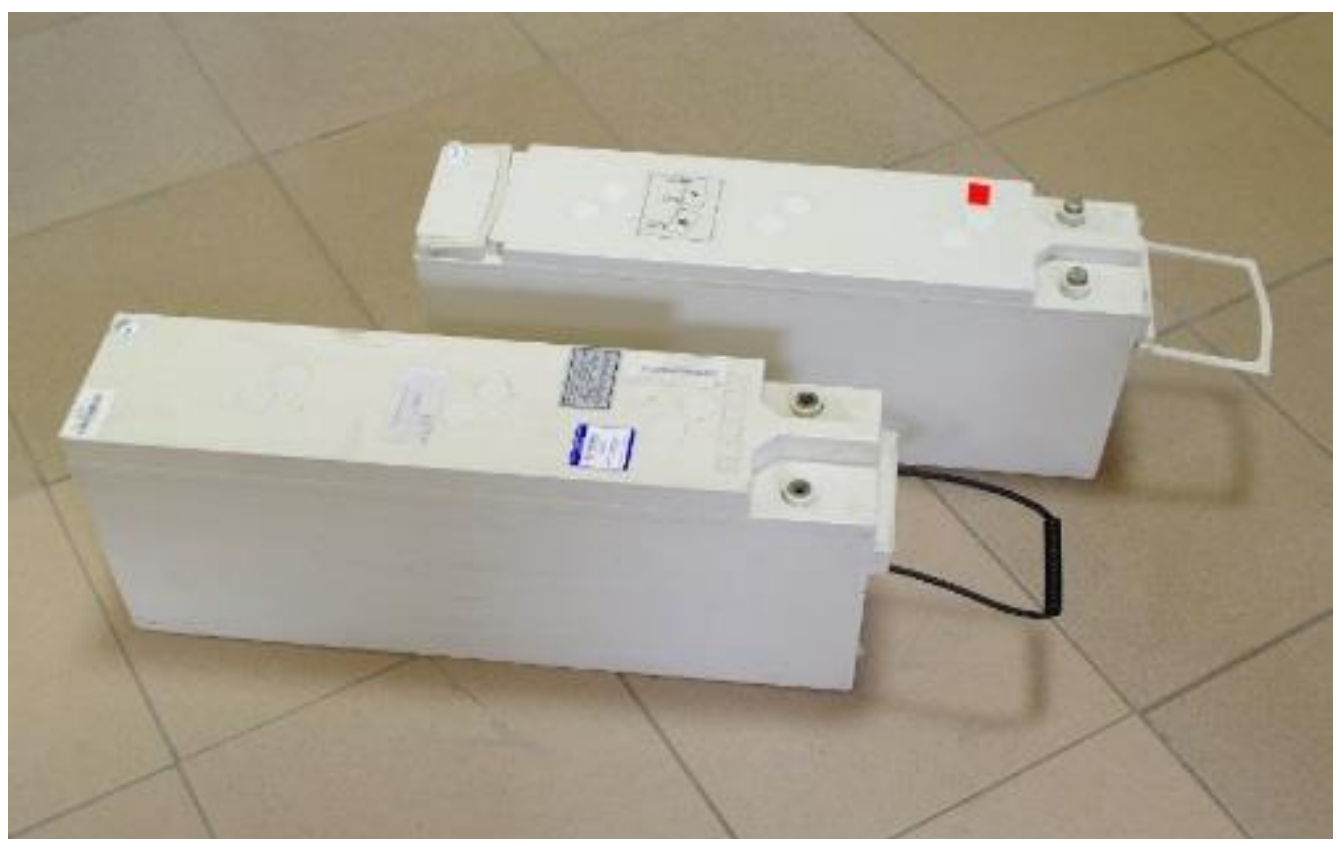

Figure 9. Brand new 6 cells $12 \mathrm{~V}$ monoblock (above), used (below).

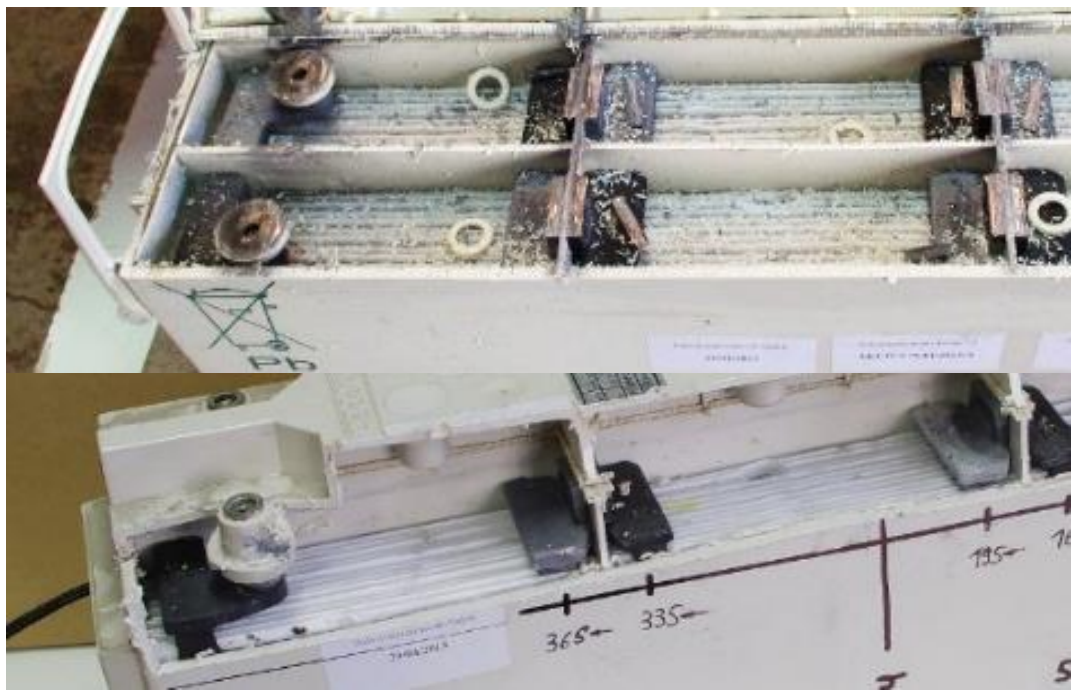

Figure 10. Cells in brand new monoblock (above), and used (below).

Some information about the $48 \mathrm{~V}$ battery's use from data storage of the supervision automatic system (a driver-cylinder device of MCSU-SU2300-600 type) was obtained (Figure 12a,b).

The average voltage of the pack during exploitation was about $53.7 \mathrm{~V}$, and the average temperature was circa $300 \mathrm{~K}$ (a room without air-condition). The span of battery temperature was between $286 \mathrm{~K}$ and $312 \mathrm{~K}$. The number of alerts (current interruptions in energy network) during use was $<20$, and the total time of outages was circa $8 \mathrm{~h}$. All recovered monoblocks were operational (no worrying signs such as high potential fluctuation or temperature increasing, either in remote systems or by supervision service, were observed). 

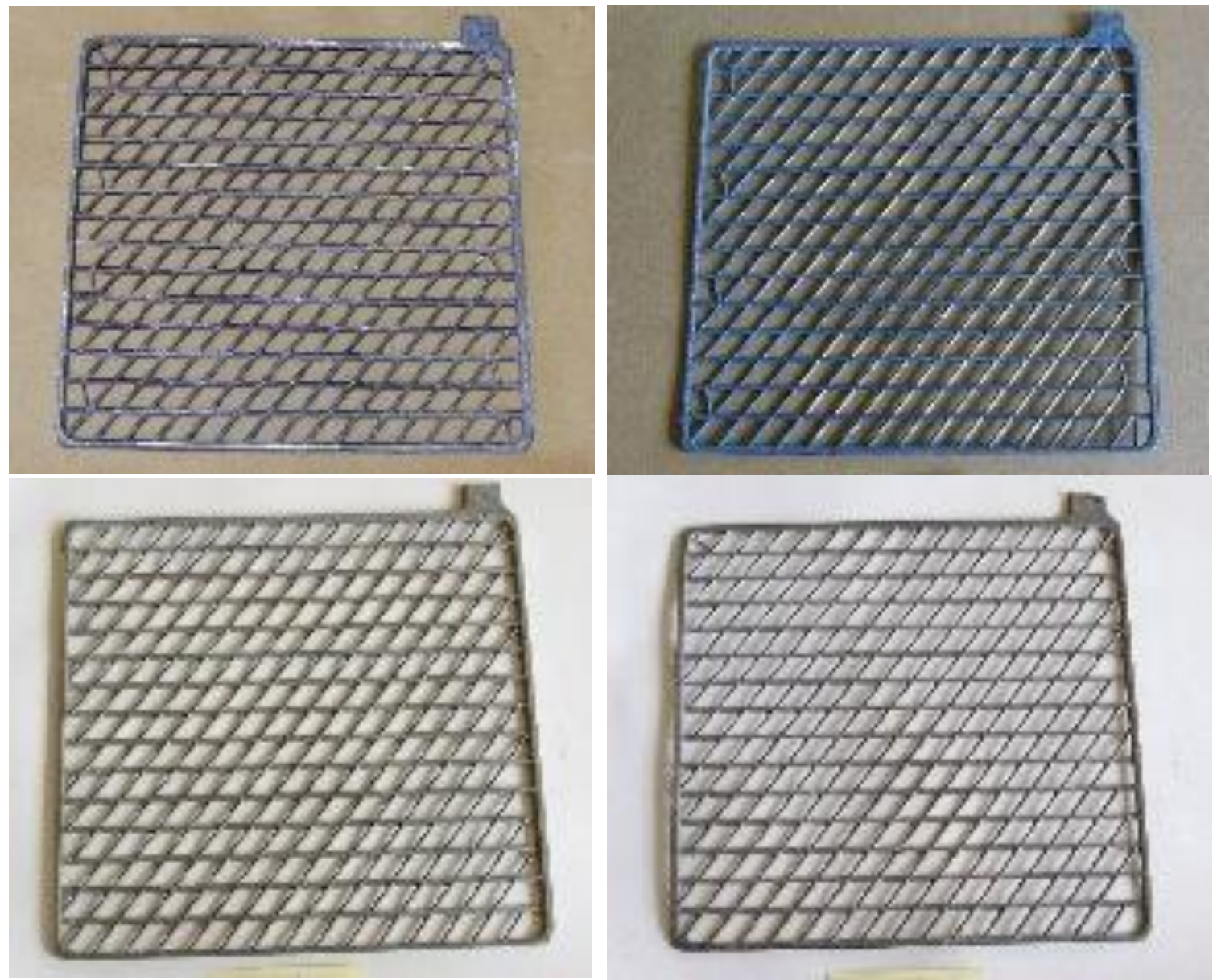

Figure 11. Grids in brand new monoblocks (above), and used (below); (+) left (-) right.

a)

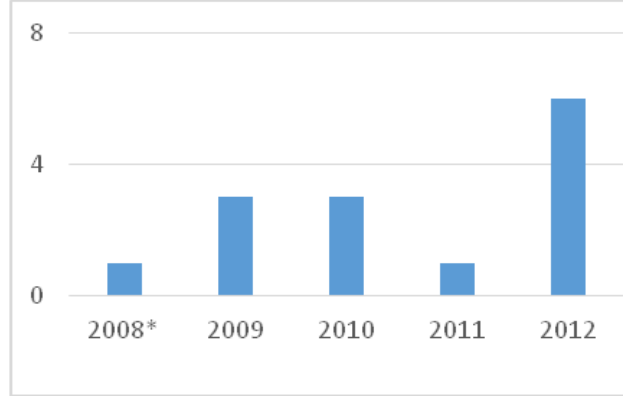

b)

- 286-293K

- 294-299K

- $300 \mathrm{~K}$

$=301 \mathrm{~K}$

- $302 \mathrm{~K}$

- $303 \mathrm{~K}$

- $304-312 \mathrm{~K}$

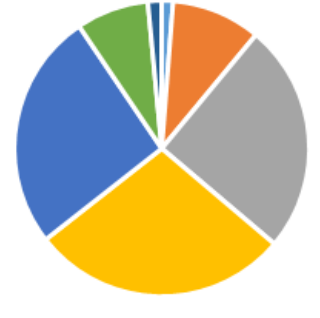

Figure 12. Number of discharges (a) and temperature values (b) of tested $48 \mathrm{~V}$ battery during operation in emergency power supply systems (* installation in second half of 2008 year).

The research consisted of float charge tests of systems containing $48 \mathrm{~V}$ batteries of $100 \mathrm{Ah}$ (the batteries after operation in emergency power supply systems, and the new ones). A flow current test was performed at $54.0 \mathrm{~V}(13.5 \mathrm{~V} /$ monoblock) in cycles of 33, 66 and 99 days, using laboratory power supply RXN (voltage range 0-60 V, current range 0-5 A). Measurements of internal resistance and voltage of both the battery and each single monoblock were performed once a day, during float charge, using Hioki device model 3554. After 33, 66, and 99 days of float charge, the circuit was unplugged. The batteries were left for $2 \mathrm{~h}$ at open current circuit and the electrochemical impedance spectroscopy (EIS) measurement of single $12 \mathrm{~V}$ monoblock was performed using a BioLogic CLB 2000 galvanostat-potentiostat with $20 \mathrm{~A}$ current booster. EIS experiments were run with AC amplitude of 
$40 \mathrm{mV}$ over the frequency range of $10^{3} \div 5 \times 10^{-3} \mathrm{~Hz}$ (10 points per decade). Impedance data were analyzed using ZView2 software (Scribner Associates Inc., Southern Pines, NC, USA).

Finally, the $48 \mathrm{~V}$ battery was discharged using Digatron BNT 50-100-3 (voltage range 5-100 V, current range $0.05-50 \mathrm{~A}$ ) by $\mathrm{I}_{10}$ current until the voltage of $43.2 \mathrm{~V}$ was reached. The aim of the measurement was to assess changes in the capacity of a $48 \mathrm{~V}$ battery and/or single $12 \mathrm{~V}$ monoblocks, and to link these changes with the aforementioned measurements. Next, the $48 \mathrm{~V}$ battery was plugged again into laboratory power supply and a subsequent cycle of float charge started.

\section{Conclusions}

Two different approaches were implemented to determine the premature capacity loss effect in batteries operating in backup power sources of telecommunication antenna stations. The first approach consisted of taking measurements of voltage and resistance change of $12 \mathrm{~V}$ old and new monoblocks as a function of time. Slight changes in voltage and resistance were recorded; however, no visible trend was found which could indicate the beginning of a PCL effect. In turn, electrochemical impedance spectroscopy enabled us to detect resistance changes which could be attributed to the beginning of the PCL effect. This method is promising, but its success depends on the choice of equivalent circuit, which is not universal. It seems that the choice of the frequency range during experiments is crucial to obtaining reliable results. One additional advantage of EIS technique is its non-disruptive application i.e., the backup power system does not need to be switched off before the test, as it is in the case of direct capacity measurement tests.

Author Contributions: W.M.-participation in the development of the project concept, participation in the analysis and development of results, management and content-related supervision. E.J.-sample preparation for measurements, performance of experiments, participation in the analysis and development of results, responsible for comments in the publication. M.B.-participation in the development of the project concept, participation in the analysis and development of results, development of research methods, responsible for writing the paper. P.H.-participation in the development of the project concept, participation in the analysis and development of results, development of research methods, responsible for writing the paper. R.S.-participation in the development of the project concept, participation in the analysis and development of results.

Funding: The National Centre for Research and Development, Poland: PBS1/B4/3/2012.

Acknowledgments: Research carried out by the project financed by the Polish National Centre for Research and Development (PBS1/B4/3/2012- “Diagnosis of early recognition of the PCL-phenomenon in lead-acid batteries to increase the reliability of emergency power supply systems"). Authors are grateful to Ph.D. Michał Stepień for his assistance in impedance data analysis and to Prof. Krzysztof Fitzner for valuable discussion.

Conflicts of Interest: The authors declare no conflict of interest.

\section{References}

1. Sato, S.; Kawamura, A. A new estimation method of state of charge using terminal voltage and internal resistance for lead acid battery. In Proceedings of the Power Conversion Conference, Osaka, Japan, 2-5 April 2002; Volume 2, pp. 565-570.

2. Zhendong, Z.; Zihan, L.; Nan, H. The VRLA battery internal resistance on-line measuring device. In Proceedings of the 2012 International Conference on Information Management, Innovation Management and Industrial Engineering (ICIII), Sanya, China, 20-21 October 2012; pp. 404-406.

3. Baraniak, M.; Jankowska, E.; Budzyński, M.; Lula, M.; Majchrzycki, W. Report IMN-CLAiO No. 6093.01 in Polish; Institute of Non-Ferrous Metals: Poznań, Poland, 2012.

4. Majchrzycki, W.; Jankowska, E.; Baraniak, M. Report IMN-CLAiO No. 6436.01 in Polish; Institute of Non-Ferrous Metals: Poznań, Poland, 2013.

5. Abraham, P.; Bača, P.; Vaculík, S. Resistivity and Impedance Changes of Lead-Acid Accumulator. ECS Trans. 2014, 48, 303-308. [CrossRef]

6. Gençten, M.; Dönmez, K.B.; Şahin, Y.; Pekmez, K.; Suvac, E. Voltammetric and electrochemical impedimetric behavior of silica-based gel electrolyte for valve-regulated lead-acid battery. J. Solid State Electrochem. 2014, 18, 2469-2479. [CrossRef] 
7. Shih, H.; Lo, T.-C. Electrochemical Impedance Spectroscopy for Battery Research and Development Technical Report No 31; Solartron: Farnborough, UK, 1996.

8. Fasih, A. Modeling and Fault Diagnosis of Automotive Lead-Acid Batteries. Master's Thesis, The Ohio State University, Columbus, OH, USA, 2 April 2006.

9. Moseley, P.T.; Garche, J.; Parker, C.D.; Rand, D.A.J. Valve-Regulated Lead-Acid Batteries, 1st ed.; Elsevier Science: Amsterdam, The Netherlands, 2004; ISBN 9780080474731.

10. Pavlov, D. Lead-Acid Batteries: Science and Technology, 2nd ed.; Elsevier Science: Amsterdam, The Netherlands, 2017; ISBN 9780444595607.

11. Łęgosz, Z. Czy baterie VRLA mogą żyć 20 lat? Przedwczesna utrata pojemności-Fundamentalny problem baterii VRLA. Wiadomości Elektrotechniczne 2001, R. LXIX, 111-115.

12. Calábek, M.; Micka, K.; Bača, P.; Křivák, P.; Šmarda, V. Resistance changes and premature capacity loss in lead battery plates. J. Power Sources 1996, 62, 161-166. [CrossRef]

13. Hollenkamp, A.F. Premature capacity loss in lead/acid batteries: A discussion of the antimony-free effect and related phenomena. J. Power Sources 1991, 36, 567-585. [CrossRef]

14. Kosai, M.; Yasukawa, S.; Osumi, S.; Tsubota, M. Effect of antimony on premature capacity loss of lead/acid batteries. J. Power Sources 1997, 67, 43-48. [CrossRef]

15. Pavlov, D. Effect of corrosion layer on phenomena that cause premature capacity loss in lead/acid batteries. J. Power Sources 1994, 48, 179-193. [CrossRef]

16. Pavlov, D.; Petkova, G.; Dimitrov, M.; Shiomi, M.; Tsubota, M. Influence of fast charge on the life cycle of positive lead-acid battery plates. J. Power Sources 2000, 87, 39-56. [CrossRef]

17. Shiomi, M.; Okada, Y.; Tsuboi, Y.; Osumi, S.; Tsubota, M. Study of PCL mechanism: Influence of grid/PAM state on PCL. J. Power Sources 2003, 113, 271-276. [CrossRef]

18. Huet, F. A review of impedance measurements for determination of the state-of-charge or state-of-health of secondary batteries. J. Power Sources 1998, 70, 59-69. [CrossRef]

19. Blanke, H.; Bohlen, O.; Buller, S.; De Doncker, R.W.; Fricke, B.; Hammouche, A.; Linzen, D.; Thele, M.; Uwe Sauer, D. Impedance measurements on lead-acid batteries for state-of-charge, state-of-health and cranking capability prognosis in electric and hybrid electric vehicles. J. Power Sources 2005, 144, 418-425. [CrossRef]

20. Karden, E.; Buller, S.; De Doncker, R.W. A method for measurement and interpretation of impedance spectra for industrial batteries. J. Power Sources 2000, 85, 72-78. [CrossRef]

21. Diard, J.-P.; Le Gorrec, B.; Montella, C. EIS study of electrochemical battery discharge on constant load. J. Power Sources 1998, 70, 78-84. [CrossRef]

22. Karden, E.; Buller, S.; De Doncker, R.W. A frequency-domain approach to dynamical modeling of electrochemical power sources. Electrochim. Acta 2002, 47, 2347-2356. [CrossRef]

23. Wei, Z.; Tseng, K.J.; Wai, N.; Lim, T.M.; Skyllas-Kazacos, M. Adaptive estimation of state of charge and capacity with online identified battery model for vanadium redox flow battery. J. Power Sources 2016, 332, 389-398. [CrossRef]

24. Wei, Z.; Bhattarai, A.; Zou, C.; Meng, S.; Lim, T.M.; Skyllas-Kazacos, M. Real-time monitoring of capacity loss for vanadium redox flow battery. J. Power Sources 2018, 390, 261-269. [CrossRef]

25. Barsoukov, E.; Macdonald, J.R. (Eds.) Impedance Spectroscopy Theory, Experiment, and Applications, 2nd ed.; John Wiley \& Sons, Inc.: Hoboken, NJ, USA, 2005.

26. Zhu, W.H.; Zhu, Y.; Tatarchuk, B.J. A simplified equivalent circuit model for simulation of Pb-acid batteries at load for energy storage application. Energy Convers. Manag. 2011, 52, 2794-2799. [CrossRef]

(C) 2018 by the authors. Licensee MDPI, Basel, Switzerland. This article is an open access article distributed under the terms and conditions of the Creative Commons Attribution (CC BY) license (http:// creativecommons.org/licenses/by/4.0/). 